\title{
Radiodifusão Comunitária no Território Sertão do São Francisco ${ }^{1}$
}

\author{
Érica Daiane da Costa Silva ${ }^{2}$ \\ Karine Pereira da Silva ${ }^{3}$
}

\section{Resumo}

Este artigo apresenta os resultados da primeira etapa do Projeto de Extensão Comunicação Comunitária no Território Sertão do São Francisco, realizado pelo Departamento de Ciências Humanas da Universidade do Estado da Bahia (Campus III Juazeiro) nos anos de 2008 e 2009, com o propósito de mapear e elaborar diagnóstico da radiodifusão comunitária no Território Sertão do São Francisco. Para tanto, foram realizadas visitas aos municípios que compõem o Território, onde foram aplicados questionários e feitas entrevistas com as/os comunicadores/as populares. A partir da observação de aspectos como formação e gestão das emissoras, participação popular, programação e sustentabilidade e de dados obtidos no site do Ministério das Comunicações, foi feita análise quantitativa e qualitativa das rádios comunitárias e sistemas de alto-falante existentes nas cidades que compõem o Território de Identidade Sertão do São Francisco.

Palavras- Chave: Radiodifusão comunitária, Desenvolvimento local, Sertão do São Francisco.

\begin{abstract}
This article presents the results of the first stage of the Community Communication Extension Project in the Wilderness Territory San Francisco, conducted by the Department of Humanities at the University of Bahia (Campus III - Juazeiro ) in 2008 and 2009 , for the purpose of map and elaborate diagnosis of community broadcasting in the Hinterland of the San Francisco Territory. To this end, visits were made to the municipalities that make up the territory, where questionnaires were applied and interviews made with communicators popular . From the observation of aspects such as training and management of stations, popular participation, programming and sustainability and data obtained in the Ministry of Communications site was made

\footnotetext{
${ }^{1}$ Artigo apresentado como relato de monitoria do Projeto de Extensão Comunicação Comunitária no Território Sertão do São Francisco, desenvolvido no Departamento de Ciências Humanas da Universidade do Estado da Bahia, sob a coordenação das docentes Céres Santos e Verbena Mourão.

${ }^{2}$ Pós-Graduada em Ensino da Comunicação Social pela Universidade do Estado da Bahia e Graduada em Comunicação Social - Jornalismo em Multimeiospela mesma Universidade. Monitora do Projeto de ExtensãoComunicação Comunitária no Território Sertão do São Francisco em 2008.

${ }^{3}$ Graduada em Comunicação Social - Jornalismo em Multimeios da Universidade do Estado da Bahia. Monitora do Projeto de ExtensãoComunicação Comunitária no Território Sertão do São Francisco em 2009.
} 
quantitative and qualitative analysis of community radio stations and existing speaker systems in the cities that make up Identity Territory Hinterland San Francisco.

Key -words : Community Broadcasting, Local development, Hinterland San Francisco

\section{Sumario}

Este artículo presenta los resultados de la primera etapa del Proyecto de Extensión Comunicación comunitaria en el territorio yermo San Francisco, realizada por el Departamento de Humanidades de la Universidad de Bahía ( Campus III - Juazeiro ) en 2008 y 2009 , con el propósito de el mapa y la elaboración de un diagnóstico de la radiodifusión comunitaria en la zona de influencia del Territorio de San Francisco. Con este fin, se realizaron visitas a los municipios que conforman el territorio, donde se aplicaron cuestionarios y entrevistas realizadas con los comunicadores popular. De la observación de aspectos tales como la formación y la gestión de las estaciones, la participación popular, la programación y la sostenibilidad y los datos obtenidos en el Ministerio de Comunicaciones sitio se hizo un análisis cuantitativo y cualitativo de las radios comunitarias y los sistemas de altavoces existentes en las ciudades que componen Territorio identidad Hinterland San Francisco.

Palabras-clave: Comunidad de Radiodifusión, desarrollo local, la zona de influencia de San Francisco

\section{Introdução}

A limitada produção científica acerca da utilização das mídias comunitárias no Brasil é reflexo do pouco entendimento acerca da importância do uso da radiodifusão comunitária em benefício do desenvolvimento local.

Neste sentido, a necessidade de conhecer a realidade da radiodifusão comunitária no Território do Sertão do São Francisco que compreende as cidades de Campo Alegre de Lourdes, Casa Nova, Canudos, Curaçá, Juazeiro, Pilão Arcado, Remanso, Sento Sé, Sobradinho e Uauá, localizadas no estado da Bahia, instigou a elaboração do projeto de extensão Comunicação Comunitária no Território Sertão do São Francisco.

O referido projeto objetiva identificar a existência de Rádios Comunitárias (RadCom's) e sistemas de alto-falantes, que estejam ou não em funcionamento, nestas cidades para, a partir disso, inferir sobre o perfil destes veículos e realizar ações que venham a contribuir na formação das/dos comunicadores populares. 


\section{fracs}

\section{Revista ComSertões}

Para desenvolvimento desse projeto, tomamos como base as rádios comunitárias e os sistemas de alto-falantes existentes nessas cidades, bem como as ações desenvolvidas pelo Instituto Regional da Pequena Agropecuária Apropriada (IRPAA) e pelo Setor de Comunicação e Audiovisual da Diocese de Juazeiro (SEDICA) que tem atuado na formação das/os comunicadores populares e na produção de programas para emissoras comunitárias.

Neste artigo, discorreremos sobre aspectos relacionados à formação, gestão, sustentabilidade e programação das emissoras, além de abordar a legislação da radiodifusão comunitária e a participação popular neste contexto. A intenção é refletir sobre a distância existente entre o conceito de Comunicação Comunitária, defendido por alguns teóricos, e a prática observada nas rádios e alto-falantes em funcionamento no Território Sertão do São Francisco, considerando a ausência de formação política da comunidade onde o meio está inserido como a principal causa de tal distância.

\section{Metodologia}

Para dar início à primeira etapa da pesquisa, a equipe formada pelos discentes Marcos Vinicius Gonçalves Santana, AlinneSuanne Tores, Érica Daiane da Costa Silva, Laura Oliveira Ferreira e Karine Pereira da Silva e as docentes Céres Santos e Verbena Mourão, confeccionou o questionário a ser aplicado em cada emissora. Para identificar as rádios comunitárias e sistemas de alto-falante existentes no Território, além de pesquisa feita no site do Ministério das Comunicações, contamos com a colaboração do SEDICA que é pioneiro na atuação com a comunicação comunitária no território e mantém contato com as/os comunicadores populares da região. A partir disso, foi montado um cronograma de viagem aos municípios para aplicação dos questionários e realização das entrevistas.

Os dados coletados em cada visita eram socializados na equipe que, por sua vez, com base nos estudos acerca da temática trabalhada, fazia avaliação das informações obtidas. Através de leituras e discussões realizadas pela equipe acerca de temas como educomunicação, legislação da radiodifusão comunitária (Lei 9.612/98) e Tv comunitária no Brasil, o embasamento teórico foi sendo construído paralelo ao cumprimento do cronograma de visitas às cidades. 
Após o período de coleta de dados, verificou-se que no estado da Bahia há um total de 175 licenças para funcionamento de rádios comunitárias, destas 146 são licenças definitivas. No território Sertão do São Francisco existem 50 pedidos registrados no Ministério das Comunicações, sendo: 6 rádios em operação (5 licenças definitivas); 2 autorizadas; 3 cadastradas (aguardando aviso de habilitação); 3 pedidos sendo analisados e 36 pedidos arquivados ${ }^{4}$.

Foram aplicados 18 questionários e feitas 19 entrevistas em 20 entidades, sendo que 10 são veículos em funcionamento (6 rádios e 4 sistemas de alto-falantes), 7 desativadas (6 rádios e 1 alto-falante) e 3 rádios que nunca funcionaram. Os questionários foram respondidos por membros da diretoria das rádios ou das associações de radiodifusão que existem hoje no Território.

A compilação dos dados, após aplicação de todos os questionários, foi feita pelas monitoras, contando com a revisão da coordenadora do projeto. A partir dos dados obtidos foram confeccionadas tabelas que serviram de suporte para escrita deste artigo, bem como irão fundamentar a publicação final do trabalho prevista para dezembro de 2009.

\section{A realidade das Rádios Comunitárias no Território Sertão do São Francisco}

A partir das respostas dos questionários foi traçado um perfil da radiodifusão comunitária no Território Sertão do São Francisco. A análise dos dados coletados foi feita com base,principalmente, nas contribuições de autores como CiciliaPeruzzo (2003) e Adriane Lorenzon (2009), bem como teóricos que tem se debruçado sobre o assunto, e na compreensão da equipe sobre a temática.

A comunicação comunitária entendida neste artigo corresponde à utilização de um meio de comunicação pela e para comunidade, que percebe a contribuição deste meio para o desenvolvimento local. Para Peruzzo (2003, p. 246) "a comunicação comunitária diz respeito a um processo comunicativo que requer o envolvimento das pessoas de uma 'comunidade', não apenas como receptora de mensagens mas como

${ }^{4}$ Dados do Ministério das Comunicações: http://www.mc.gov.br/radio-comunitaria -acesso em 20 de julho de 2009. 
protagonista dos conteúdos e da gestão dos meios de comunicação". De acordo com o Artigo $1^{\circ}$ da Legislação brasileira da Radiodifusão Comunitária ${ }^{5}$,

Denomina-se Serviço de Radiodifusão Comunitária a radiodifusão sonora, em frequiência modulada, operada em baixa freqüência e cobertura restrita, outorgada a fundações e associações comunitárias, sem fins lucrativos, com sede na localidade de prestação de serviço.

\section{Formação e gestão das emissoras}

O processo de estruturação de um meio comunitário em determinada localidade deve decorrer da necessidade e compreensão da finalidade da mídia comunitária, reflexo de mobilização e engajamento social da população beneficiada. Entretanto, em muitos casos, a iniciativa de criação de veículos comunitários parte de uma pessoa ou pequenos grupos, sem o envolvimento da maioria dos moradores da comunidade.

Esta situação foi constatada em grande parte das cidades pesquisadas, ao identificarmos que a proposta de criação da rádio comunitária ou serviço de alto-falante partiu de um pequeno grupo de pessoas, em sua maioria ligada aos movimentos sociais, que já tinha alguma afinidade ou interesse em discutir comunicação. A comunidade, nestes casos, é convidada a discutir e aprovar a proposta apresentada pelo grupo.

A maioria das cidades não tem nenhum meio de comunicação local, o que contribuiu para a instalação das emissoras comunitárias. A finalidade, a princípio, é a de prestação de serviços, tendo a promoção do desenvolvimento local como fator secundário. Destaca-se que em apenas uma das dez cidades a existência do sistema de alto-falante impulsionou a criação da rádio, ratificando assim o crescimento político pelo qual a comunidade passou.

Conforme foi constatado, na maioria dos casos, os responsáveis pelas rádios são pequenos grupos ou movimentos sociais e populares que não dispõem de recursos financeiros suficientes para a compra dos equipamentos necessários para a rádio ir ao ar. Identificou-se que a comunidade, após ser despertada, se envolve na aquisição e instalação dos equipamentos necessários para o funcionamento das rádios, colaborando, inclusive na organização de festas, bingos, rifas, etc. Doações de equipamentos novos e

\footnotetext{
${ }^{5}$ Lei 9.612 publicada no Diário Oficial da União de 20/02/98.
} 


\section{fress}

\section{Revista ComSertões}

usados, doações financeiras de pessoas que tem cargos políticos, de entidades religiosas, ou do próprio presidente da emissora, além de recursos da associação mantedora, são também citadas como outras formas de angariar recursos.

Vale ressaltar a presença da Igreja Católica no incentivo à criação das rádios e na formação das/dos comunicadores populares nessa região, através do Setor Diocesano de Comunicação e Audiovisual (SEDICA), como apontam as informações contidas nos questionários e entrevistas.

No que se refere a outorga concedida pelo Ministério das Comunicações para funcionamento das RadCom's, além das críticas referente à burocracia estabelecida pela Lei 9.612/98, a lentidão na análise dos processos faz com que as rádios aguardem mais de cinco anos para receberem licença para funcionar, isto quando conseguem ultrapassar os critérios exigidos para envio de solicitação para prestar o serviço de radiodifusão.

Quanto à gestão, constatou-se que geralmente a diretoria da rádio é composta pelas mesmas pessoas que lideraram o processo inicial de reivindicação e instalação do veículo, sendo estas eleitas em assembleias. Em alguns casos, este modelo de gestão assemelha-se às emissoras comerciais devido, principalmente, a existência de hierarquia nas tomadas de decisões. Este pode ser considerado um grave problema, uma vez que as emissoras comerciais visam o lucro e a centralização do poder, enquanto as comunitárias surgem com o propósito da contra-hegemonia, ou seja, são espaços democráticos, sem fins lucrativos, gestados pela sociedade civil. Contudo, é importante destacar que estes fatores devem-se, segundo Lorenzon (2009), à falta de consciência da comunidade sobre a importância e a finalidade do veículo comunitário.

Nunes (2002) chama atenção para um dos principais problemas que afetam a realidade da radiodifusão comunitária no país. Por lei, é proibida a utilização das RadCom's para fins político-partidários, no entanto, o que se observa, de modo geral, é a utilização desses veículos em benefício de interesses pessoais de determinadas pessoas, uma vez que grande parte das concessões pertencem a representantes políticos. Isso permite o uso da radiodifusão comunitária, sobretudo em períodos eleitorais, na promoção de candidatos a vereadores, prefeitos, deputados, entre outros cargos políticos ou de confiança de determinados governos. 


\section{Participação popular}

O envolvimento das pessoas enquanto sujeitos ativos é essencial para a existência da comunicação comunitária. Neste sentido, podemos considerar as afirmações de Teixeira (2001) sobre participação cidadã, quando diz que esta significa "fazer parte" do coletivo dentro de um processo social.

Peruzzo (2003, p. 250), ao tratar da comunicação comunitária de base democrática, define-a como "um processo em que todo receptor de mensagens dos meios de comunicação tem o potencial de se tornar sujeito da comunicação, um emissor". Mas a autora também alerta para o fato de que nem todos os meios de comunicação tidos como comunitários são abertos a tal participação, conforme defende Teixeira (2001).

$\mathrm{Na}$ realidade da radiodifusão comunitária existente no Território do São Francisco, percebe-se que o entendimento que se tem de participação popular nos veículos comunitários, na maior parte das emissoras, segue o padrão de participação do público-ouvinte das rádios comerciais. Na avaliação das/dos entrevistados na pesquisa, esta participação restringe-se ao usufruto da programação para prestação de serviços, à colaboração em forma de doações financeiras, à participação por telefone nos programas ao vivo, ou, em menor escala, à produção de programas, geralmente feito por entidades ou movimentos sociais atuantes na cidade onde a rádio está situada.

Pouco se constata a participação das pessoas, sócias ou não da emissora, nas tomadas de decisões, na definição da linha editorial e grade de programação, na administração dos recursos financeiros, ou seja, não há uma participação ampliada do cidadão, como apresenta Peruzzo (2003) em "Mídia comunitária, liberdade de comunicação e desenvolvimento". Neste texto, a autora também discorre sobre os vários níveis de participação presentes na comunicação comunitária, descrevendo-os como níveis elementares: o da recepção; a contribuição com entrevistas, cartas, depoimentos; e níveis mais elevados que possibilita a atuação da pessoa enquanto "sujeito ativo, como protagonista da elaboração de mensagens [...] e no planejamento e na gestão do canal de comunicação" ( p. 248).

\section{Programação}


Uma das principais diferenças entre os veículos comunitários e comerciais dizem respeito à programação. As rádios comerciais atendem aos interesses capitalistas com o propósito de estimular o consumo e, consequentemente, resulta no aumento nas desigualdades sociais, apesar da legislação estabelecer o oposto.

Já as RadCom's se propõem a ser uma alternativa a esse modelo de comunicação, priorizando em sua programação os interesses coletivos de onde está inserida. No entanto, na programação das rádios pesquisadas verifica-se que há, na maior parte dos veículos em operação, uma reprodução da programação veiculada nas emissoras comerciais. Esta realidade das rádios em funcionamento no Território é referendada por Lorenzon $(2009$, p. 23$)$ ao afirmar que isso ocorre "sob a justificativa equivocada de alguns diretores [e demais membros] das comunitárias de que é preciso competir com as comerciais para ganhar audiência".

Um dos reflexos disso é a programação ser predominantemente preenchida por programas musicais, os quais, em sua maioria, não possuem conteúdo educativo. Parte das canções tocadas reforçam a ideologia da existência de uma massa alienável e reproduzem discursos opressores - característica já bastante presente no circuito das emissoras comercias - que não contribuem para a formação de uma consciência crítica e uma prática cidadã. Além disso, há pouca valorização das produções locais, priorizando artistas consagrados pela indústria cultural.

A produção dos programas fica a cargo das instituições sociais e pessoas físicas que fazem parte da associação da radiodifusão, sendo que a maioria dos responsáveis pelos programas são os mesmo que compõem a diretoria da emissora.

Além da programação musical, são produzidos programas de cunho religioso, com destaque para programas produzidos pelas igrejas evangélicas; e em menor número, os infantis e jornalísticos. Este último, muitas vezes restringe-se a noticiar fatos policiais e denunciar problemas cotidianos da população.

Dioclécio Luz, na segunda edição de seu livro "Rádios Comunitárias: trilha apaixonada e bem-humorada do que é e de como fazer rádios comunitárias na intenção de mudar o mundo" problematiza a existência de programas policiais e resumo de novelas na grade de programação de algumas RadCom's, algo bastante comum nas rádios e alto-falantes comunitários mapeados no Território Sertão do São Francisco. 
Luz argumenta que os programas policiais em nada contribuem para a promoção dos direitos humanos, ao contrário, acabam sendo formas de reforçar o poder repressor do Estado, uma vez que só é mostrada principalmente a visão da polícia. Os resumos de novelas, de acordo com o autor, também podem ser tirados da programação, e como sugestão aponta a produção de radionovelas que tratem de temas de interesse da comunidade e valorizem a cultura e artistas locais.

Esta redução na produção de programas é resultado da falta de formação/mobilização e de recursos financeiros suficientes para arcar com a realização de tais ações, uma vez que trata-se de emissoras comunitárias que não tem fins lucrativos.

Neste sentido, observamos que, de modo geral, não há um engajamento entre a prática e a finalidade da mídia comunitária no Território, uma vez que o modelo de comunicação comunitária deve transmitir

uma programação de interesse social vinculada à realidade local, não tem fins lucrativos, contribui para ampliar a cidadania, democratizar a informação, melhorar a educação informal e o nível cultural dos receptores sobre temas diretamente relacionados às suas vidas. (PERUZZO, 2007, p. 01).

Contudo, é importante destacar ainda o protagonismo da comunidade neste processo de troca de informação. Nas comunidades rurais, principalmente, a vida social da populaçãoestá bastante atrelada ao rádio. Com base nisso, Nunes (2002, p. 66) reforça o papel das rádios comunitárias, considerando-as como importantes canais por meio dos quais "começam a expressar-se os próprios vizinhos, as instituições intermediárias, culturais, sociais, políticas e esportivas de cada localidade, o que de nenhum modo será possível sem a existência desses meios locais".

\section{Sustentabilidade}

Um dos principais problemas identificados na radiodifusão comunitária refere-se à inexistência de financiamento público que garanta a manutenção e sustentabilidade do serviço. A própria legislação contribui para fomentar a dependência das rádios 
comunitárias a formas alternativas de adquirir financiamento para custear as despesas da emissora (doações da comunidade, realização de bingos, taxas de manutenção pagas pelos associados, entre outras). O artigo 18 da Lei 9.612/98 diz que: "as prestadoras do Serviço de Radiodifusão Comunitária poderão admitir patrocínio, sob a forma de apoio cultural, para os programas a serem transmitidos, desde que restritos aos estabelecimentos situados na área da comunidade atendida".

Nesse sentido, nem todas as emissoras cumprem as determinações da legislação contidas no artigo 18. Algumas delas chegam a veicular propagandas ou até mesmo a vender horários da sua programação. Devido a falta de um fundo específico de financiamento e a necessidade de custear as despesas com água, luz, telefone, manutenção de equipamentos, ajuda de custo para os colaboradores, entre outras demandas fundamentais para o funcionamento do serviço, muitas rádios acabam fechando.

\section{Criminalização e repressão}

No Brasil prevalece um modelo de comunicação que cada vez mais busca firmar-se como modelo oficial, ditando padrões e regras a serem seguidas pelos demais meios de comunicação e informação. Esta mídia hegemônica tem agido no sentido de marginalizar, criminalizar esta outra mídia (dita alternativa) que se propõe a desconstruir este sistema. Quando esta estratégia não é suficiente, a comunicação comunitária passa a ser vítima também da repressão do Estado.

A realidade do Território Sertão do São Francisco não se difere do restante do país. Das emissoras que hoje possuem licença para funcionamento ou as que encontramse desativadas, muitas já foram notificadas pela Polícia Federal que, em cumprimento à ordem judicial solicitada pela Agência Nacional das Telecomunicações (ANATEL), invade os estabelecimentos, quebrando ou confiscando equipamentos ou prendendo as pessoas responsáveis pela emissora. Atualmente, há comunicadores que, mesmo não estando mais atuando nos veículos (pois não estão mais em operação), ainda respondem à processos judiciais.

Em muitos casos, a ação se justifica pelo funcionamento da rádio sem concessão ou pelo descumprimento do Decreto $2.615 / 98^{6}$, mais precisamente dos Artigos $5^{\circ}$ e $6^{\circ}$

\footnotetext{
${ }^{6}$ Decreto queregulamenta o Serviço de Radiodifusão Comunitária publicado em 03/06/98.
} 
que estabelece, respectivamente, que a potência a ser irradiada pela RadCom deve ser igual ou inferior a 25 Watts e a cobertura deve ser restrita a uma "área limitada por um raio igual ou inferior a mil metros a partir da antena transmissora".

Algumas rádios que funcionaram sem a autorização, não possuíam programação fixa com receio de serem identificadas e fechadas pelos órgãos repressores (ANATEL e Polícia Federal).

\section{Considerações Finais}

As emissoras radiofônicas comunitárias devem permitir a participação, nos variados níveis, das pessoas residentes na comunidade e devem pautar aspectos relacionados à cultura e a vida social da população, priorizando os interesses comuns, contribuindo para a consolidação de uma comunicação plural, democrática.

Considerando os veículos radiofônicos que funcionam ou já estiveram em operação no Território Sertão do São Francisco, é possível dizer que tais características foram identificadas em alguns destes. Entretanto, de modo geral, há uma distorção do entendimento da finalidade da radiodifusão comunitária. Esta problemática, na maioria dos casos não é proposital, mas decorre da carência de formação política e social, sobretudo, no processo de mobilização para instalar a emissora.

Nas entrevistas realizadas, percebemos que muitas das entidades que atualmente possuem a outorga para prestação do serviço de radiodifusão comunitária nas cidades do território, estão fincadas em interesses religiosos, políticos partidários ou lucrativos.

A ausência da formação ocasiona a existência de algumas rádios comunitárias de direito, mas que não configuram-se como tal na prática cotidiana. Conclui-se que a falta de sensibilização quanto ao uso deste instrumento em benefício do desenvolvimento local, através da conquista da cidadania, é um obstáculo na democratização da comunicação e da informação mesmo onde já existe meios de comunicação com este propósito.

\section{REFERÊNCIAS}

DUARTE, Edson. Liberdade de expressão das rádios comunitárias. Brasília: Gabinete do deputado federal Edson Duarte (PV/BA), 2004. 
Revista ComSertões

LORENZON, Adriane. Poder local no ar: municipalização das rádios comunitárias e fortalecimento de esferas públicas locais no Brasil. Brasília: Abravídeo, 2009.

LUZ, Dioclécio. Rádios Comunitárias: trilha apaixonada e bem-humorada do que é e de como fazer rádios comunitárias na intenção de mudar o mundo. 2. ed. Brasília: Produção Independente, 2004.

NUNES, Vidal Márcia. As rádios comunitárias nas campanhas eleitorais: exercício da cidadania ou instrumentalização (1998-2000). Disponível em: http://www.scielo.br/pdf/rsocp/n22/n22a06.pdf - Acesso em 12 de agosto de 2009.

PERUZZO, Cicilia M. K. Comunicação nos movimentos populares: a participação da construção da cidadania. 3. ed. Petrópolis: Vozes, 2004.

PERUZZO, Cicilia M. K. Mídia comunitária, liberdade de comunicação e desenvolvimento. In: PERUZZO, Cicilia M.K. ALMEIDA, Fernando F. de. (Org). Comunicação para cidadania. São Paulo: INTERCOM; Salvador: UNEB; 2003. p. $245-260$.

PERUZZO, Cicilia M. K. rádio comunitária, educomunicação e desenvolvimento local. Net, Rio de Janeiro , 2007. P. 69- 94. Disponível em: $<$ http://www.ciciliaperuzzo.pro.br/artigos/radio_comunitaria_educomunicacao_e_desen volvimento_local.pdf >. Acesso em: 7 jul. 2009.

TEIXEIRA, Elenaldo. O local e o global: limites e desafios da participação cidadã. São Paulo: Cortez; Recife: EQUIP; Salvador: UFBA, 2001. 